\title{
Systemic Lupus Erythematosus Induced by Autoimmune/ Inflammatory Syndrome Induced by Adjuvants. Is it Possible? Long-Term Follow-up and Literature Review
}

\author{
Agata SEBASTIAN ${ }^{1}$, Aleksandra BUTRYM ${ }^{2}$, Maria MISTERSKA SKÓRA ${ }^{1}$, \\ Arkadiusz CHLEBICKI ${ }^{1}$, Grzegorz MAZUR ${ }^{3}$, Piotr WILAND ${ }^{1}$ \\ ${ }^{1}$ Department of Internal Medicine, Division of Rheumatology, Wroclaw Medical University, Wrocław, Poland \\ ${ }^{2}$ Department of Hematology, Blood Neoplasms and Bone Marrow Transplantation, Wroclaw Medical University, Wrocław, Poland \\ ${ }^{3}$ Department of Internal and Occupational Diseases and Hypertension, Wroclaw Medical University, Wrocław, Poland
}

There are reports in the literature describing a relationship between the use of adjuvants and development of autoimmune diseases. ${ }^{1}$ In this article, we present a case of 37-year-old female patient who was hospitalized in 2010 due to severe, non-specific chest pain and purpura. Laboratory studies revealed thrombocytopenia $51 \times 10^{3}$ (normal values $140-440 \times 10^{3}$ ). Thrombotic thrombocytopenic purpura (TTP) with high titers of ADAMTS-13 antibody was diagnosed. TTP progression could not be halted despite treatment, necessitating administration of rituximab and removal of breast implants, what resulted in complete remission. Autoimmune/inflammatory syndrome induced by adjuvants (ASIA) was diagnosed retrospectively. ${ }^{2}$

Moreover, immunological studies demonstrated presence of anti-nuclear antibodies (ANA) (antiSjögren's syndrome A [anti-SSA]) which returned to normal levels after rituximab and removal of implants, and remained normal during follow-up after two years.

In 2014, the patient reported to the Rheumatology Outpatient Clinic due to symptoms of fatigue growing for over three months and mild pain in peripheral joints. Physical examination of the motor system revealed tenderness and edema of small joints in both hands. Laboratory studies demonstrated mild leukopenia $3.7 \times 10^{3} / \mathrm{uL}$ (normal values $4-10 \times 10^{3} / \mathrm{uL}$ ), reduced components of the complement system, and positive ANA (Table 1). Systemic lupus erythematosus (SLE) was diagnosed based on the Systemic Lupus International Collaborating Clinics criteria. ${ }^{3}$ Treatment with hydroxychloroquine (200 mg/day) was initiated with improvement. In 2016, the patient again experienced symptoms of fatigue; laboratory studies confirmed hypothyroidism and the presence of antithyroglobulin antibodies. Immunological studies showed increased ANA titer (anti-SSA, anti-nucleosome) as well as slightly reduced levels of C3 component of the complement system. Clinical improvement was obtained after supplementation of thyroid hormones. As determined retrospectively, the patient was six weeks pregnant at the time, but miscarried in the first trimester.

Adjuvants are substances capable of inducing severe immunological reaction. ${ }^{1,4}$ Silicone

Received: November 10, 2017 Accepted: November 11, 2017 Published online: January 15, 2018

Correspondence: Agata Sebastian, MD. Department of Internal Medicine, Division of Rheumatology, Wroclaw Medical University, 50-556 Wrocław, Poland.

Tel: 515128306 e-mail: agatasebastian@vp.pl

@2018 Turkish League Against Rheumatism. All rights reserved. 


\begin{tabular}{|c|c|c|c|c|c|}
\hline Time (year) & ANA titer & $\begin{array}{c}\text { ENA } \\
\text { specific nuclear antigens }\end{array}$ & C3 & C4 & ds-DNA \\
\hline 2010 & $1: 320$ & SSA & & & \\
\hline 2012 & $1: 100$ & - & 1.0 & 0.3 & - \\
\hline 2014 & $1: 10,000$ & $\begin{array}{c}\text { Ribosomal P } \\
\text { SSA } \\
\text { SM } \\
\text { SM/RNP } \\
\text { Nucleosome }\end{array}$ & 0.50 & 0.08 & - \\
\hline 2015 & & $\begin{array}{l}\text { SSA } \\
\text { Nucleosome }\end{array}$ & 1.0 & 0.4 & 125 \\
\hline 2016 & $1: 1,000$ & $\begin{array}{l}\text { SSA } \\
\text { Nucleosome }\end{array}$ & 0.8 & 0.3 & 68 \\
\hline
\end{tabular}

implants and other esthetic procedures are some of the best-examined adjuvants. ${ }^{5}$ It remains unelucidated why our patient developed high titers of antibodies and presented with clinical symptoms of SLE after two years of full remission of ASIA. It might be associated with the administration of rituximab. The patient had not suffered from infection or being under particular stress, which might be a provoking factor. Interestingly, in the subsequent years, we observed a decrease in her antibody titer or even complete clearance. We failed to find an explanation as to why the last blood tests showed reduced concentrations of one of the complement components, appearance of previously absent antithyroglobulin antibodies. We may only speculate that it might be related to early pregnancy and re-activation of mechanisms causing excessive stimulation of the immune system. To date, only isolated cases of ASIA associated with disturbances of thyroid function have been described in the literature. ${ }^{6}$

On the other hand, TTP may be present in $1-4 \%$ of patients with SLE and in most cases it is associated with elevated SLE activity. ${ }^{7,8}$ Presence of two antibodies, double stranded deoxyribonucleic acid and anti-SSA at the time of TTP diagnosis, is associated with the development of systemic connective tissue disease at later time. ${ }^{8}$

In conclusion, ASIA remains to be an enigmatic, poorly elucidated, and therefore, unpredictable disorder.

\section{Declaration of conflicting interests}

The authors declared no conflicts of interest with respect to the authorship and/or publication of this article.

\section{Funding}

The authors received no financial support for the research and/or authorship of this article.

\section{REFERENCES}

1. Shoenfeld Y, Agmon-Levin N. 'ASIA' - autoimmune/ inflammatory syndrome induced by adjuvants. J Autoimmun 2011;36:4-8.

2. Butrym A, Halon A, Bykowska K, Dzietczenia J, Mazur G. Acquired thrombotic thrombocytopenic purpura (TTP) induced by silicone breast implants in 37-year old woman. Thromb Res 2013;131:223-5.

3. Petri M, Orbai AM, Alarcón GS, Gordon C, Merrill JT, Fortin PR, et al. Derivation and validation of the Systemic Lupus International Collaborating Clinics classification criteria for systemic lupus erythematosus. Arthritis Rheum 2012;64:2677-86.

4. Scanzi F, Andreoli L, Martinelli M, Taraborelli $\mathrm{M}$, Cavazzana I, Carabellese $\mathrm{N}$, et al. Are the autoimmune/inflammatory syndrome induced by adjuvants (ASIA) and the undifferentiated connective tissue disease (UCTD) related to each other? A casecontrol study of environmental exposures. Immunol Res 2017;65:150-6.

5. Vera-Lastra O, Medina G, Cruz-Dominguez Mdel P, Ramirez P, Gayosso-Rivera JA, Anduaga-Dominguez $\mathrm{H}$, et al. Human adjuvant disease induced by foreign substances: a new model of ASIA (Shoenfeld's syndrome). Lupus 2012;21:128-35.

6. Watad A, David P, Brown S, Shoenfeld Y. Autoimmune/ Inflammatory Syndrome Induced by Adjuvants and 
Thyroid Autoimmunity. Front Endocrinol (Lausanne) 2017;7:150.

7. González NS, Lorenzo N, Parodis Y, Ortiz MBA, Kechida M, Perez JCR. Thrombotic thrombocytopenic purpura in a new onset lupus patient? Immunol Res
2017;65:454-8.

8. Roriz M, Landais M, Desprez J, Barbet C, Azoulay E, Galicier L, et al. Risk Factors for Autoimmune Diseases Development After Thrombotic Thrombocytopenic Purpura. Medicine (Baltimore) 2015;94:1598. 